\title{
The pig as a mixing vessel for influenza viruses: Human and veterinary implications
}

\author{
Wenjun $\mathrm{Ma}^{1}$, Robert E Kahn ${ }^{2}$ and Juergen A Richt ${ }^{*}$ \\ ${ }^{1}$ Department of Diagnostic Medicine/Pathobiology, College of Veterinary Medicine, Kansas State University, \\ Manhattan, KS, 66506, USA, ${ }^{2}$ Avian Flu Action, Warrington, Cheshire, United Kingdom \\ *Correspondence to: Juergen Richt, Email: jricht@vet.k-state.edu, Tel: +785 532 2793, Fax: +785 5324039
}

Received 15 August 2008, Revised 05 November 2008, Accepted 09 November, Published online 27 November 2008

J Mol Genet Med (2009), 3(1), 158-166

(C) Copyright The Authors: This is an open access article, published under the terms of the Creative Commons Attribution Non-Commercial License (http://creativecommons.org/licenses/by-nc/2.0/uk/). This license permits noncommercial use, distribution and reproduction of the article, provided the original work is appropriately acknowledged with correct citation details.

\begin{abstract}
Influenza A viruses are highly infectious respiratory pathogens that can infect many species. Birds are the reservoir for all known influenza A subtypes; and novel influenza viruses can emerge from birds and infect mammalian species including humans. Because swine are susceptible to infection with both avian and human influenza viruses, novel reassortant influenza viruses can be generated in this mammalian species by reassortment of influenza viral segments leading to the "mixing vessel" theory. There is no direct evidence that the reassortment events culminating in the 1918, 1957 or 1968 pandemic influenza viruses originated from pigs. Genetic reassortment among avian, human and/or swine influenza virus gene segments has occurred in pigs and some novel reassortant swine viruses have been transmitted to humans. Notably, novel reassortant $\mathrm{H} 2 \mathrm{~N} 3$ influenza viruses isolated from the US pigs, most likely infected with avian influenza viruses through surface water collected in ponds for cleaning barns and watering animals, had a similar genetic make-up to early isolates (1957) of the H2N2 human pandemic. These novel H2N3 swine viruses were able to cause disease in swine and mice and were infectious and highly transmissible in swine and ferrets without prior adaptation. The preceding example shows that pigs could transmit novel viruses from an avian reservoir to other mammalian species. Importantly, $\mathrm{H} 2$ viruses pose a substantial risk to humans because they have been absent from mammalian species since 1968 and people born after 1968 have little preexisting immunity to the $\mathrm{H} 2$ subtype. It is difficult to predict which virus will cause the next human pandemic and when that pandemic might begin. Importantly, the establishment and spread of a reassorted mammalian-adapted virus from pigs to humans could happen anywhere in the world. Therefore, both human and veterinary research needs to give more attention to potential cross-species transmission capacity of influenza A viruses.
\end{abstract}

Keyswords: Swine, influenza A virus, mixing vessel, genetic reassortment, human pandemic

\section{INTRODUCTION}

The ecology of influenza A viruses

The presence of all subtypes influenza A viruses in wild aquatic birds poses serious health risks to a wide range of animal species. Influenza A viruses are enveloped, single-, negative-stranded and segmented RNA viruses belonging to the Orthomyxoviridae family; they are highly infectious respiratory pathogens in their respective natural hosts. All 16 known hemagglutinin (HA) and 9 neuraminidase (NA) subtypes of influenza A viruses have been isolated from wild waterfowl and seabirds (Webster et al, 2006). Although some of these subtypes are non-pathogenic/nonvirulent within their natural hosts and have been present in these animal reservoirs for many centuries, various subtypes are highly virulent within their natural host 
species and to other species (Webby et al, 2007). For example, the changing role of the highly pathogenic avian influenza virus (HPAIV) H5N1 subtype in both wild and domestic ducks has recently been documented as a potential public health hazard because they are zoonotic agents with the theoretical ability - after genetic adaptation - of a human-to-human transmission, i.e., the start of a human epidemic/pandemic (Hulse-Post et al, 2005).

The ecology of influenza A viruses is dynamic and complex involving multiple host species and viral genes. Commercial poultry farms, "wet markets," (where live birds and other animals are sold), backyard poultry farms, commercial and family poultry slaughtering facilities, swine farms, human dietary habits and the global trade in exotic animals have all been implicated in the spread of influenza A viruses (Greger, 2006). The "wet markets" of Southeast Asia, where people, pigs, ducks, geese and chickens (and occasionally other animals) are in close proximity pose a particular danger to public health (Webster, 2004; Bush, 2005; Greenfeld, 2006; Lau et al, 2007).

Scientific opinion differs on the probability of future sustained human-to-human transmission, e.g., for $\mathrm{H} 5 \mathrm{~N} 1$ HPAIV, as well as on which viruses pose the greatest threat to humanity and to other species (Hilleman, 2002). The prevailing scientific view regarding a possible $\mathrm{H} 5 \mathrm{~N} 1$ epidemic is that sustained human-to-human transmission will occur at some unknown future date and that a prediction on the future virulence of $\mathrm{H} 5 \mathrm{~N} 1$ viruses to humans is very difficult to make. The H5N1 HPAIVs are possibly the greatest threat at the moment, although $\mathrm{H} 1$, $\mathrm{H} 2, \mathrm{H} 3, \mathrm{H} 7$ and $\mathrm{H} 9$ avian-derived viruses are also strong contenders as causes of potential epidemics in various species, including humans (Hilleman, 2002; Wan et al, 2008). This review will conclude that an avian influenza virus transmitted via pigs to humans poses a significant risk to cause a new influenza pandemic, possibly on the disturbing scale of the human influenza pandemic experienced during 1918-1920 (H1N1 "Spanish Flu"). Before investigating the role of swine in the influenza A viruses, it is necessary to consider the challenge which influenza A viruses pose to both human and animal health.

\section{INFLUENZA AND HUMAN HEALTH}

The history of human influenza pandemics offers important information for future events. A human influenza pandemic in 1580 that impacted Europe, Asia and Africa, significant regional epidemics in the $17^{\text {th }}$ century and further epidemics and pandemics in the $18^{\text {th }}(1729-30,1732-33$, and 1781-82), $19^{\text {th }}\left(1830-31,1833\right.$ and 1889-90) and $20^{\text {th }}$ $(1918,1957,1968)$ centuries have been documented (Crosby, 1993; Lina, 2008; Quinn, 2008). Thus the pandemic flu occurring in $1918-20$ caused by an H1N1 subtype virus (Tumpey et al, 2005) was not surprising, even if the precise source, timing and virulence could not be predicted. What has been surprising is that the human influenza pandemic of 1957-1958 (H2N2 "Asian Flu"), 1968 (H3N2 "Hong Kong Flu"), the 1976 H1N1 swine influenza outbreak in Fort Dix, NJ, the reintroduction of H1N1 in 1977 from Russia and the 1997 outbreak of the newly emerging H5N1 HPAIV in commercial poultry and humans in Hong Kong have all been less virulent in terms of their morbidity and their mortality (de Jong et al, 2000; Horimoto and Kawaoka, 2005).

These rather mild influenza pandemics/epidemics in the $20^{\text {th }}$ and $21^{\text {st }}$ century raise several significant questions: (i) Have influenza A viruses become less virulent for humans? (ii) Has modern medicine become more able to control these outbreaks than in earlier centuries? There is reasonable evidence suggesting that influenza A viruses are not becoming less virulent, nor has modern medicine been able to prevent either the beginning of a pandemic nor its immediate spread (Morse, 2007; Korteweg and Gu, 2008; Wu et al, 2008). While there is now considerable understanding of how viruses cause influenza, much research and development still needs to be done before the quantity, timeliness and effectiveness of both antiviral compounds and prophylactic vaccines can be provided "in time" in order to protect the public from a devastating future influenza pandemic (Yamada et al, 2008; Yang et al, 2008; Cheung, 2008). Nevertheless, the recent development of prepandemic influenza vaccines for the vaccination of individuals and communities is encouraging (Jennings et al, 2008).

According to the World Health Organization (WHO), since 2003 of the 387 confirmed human cases with confirmed H5N1 HPAIV infection, 63\% (245 persons) have died (WHO, 2008a). It should be noted that $90 \%$ of H5N1 cases (348) and 91\% of H5N1-related deaths (223) have been in only five countries: Indonesia, Vietnam, Egypt, Thailand and China. These data support the prediction of the Lowy Institute in Australia that if an influenza pandemic does occur, $95 \%$ of deaths will be in developing countries (McKibbon and Sidorenko, 2006). Nevertheless, since 2005, the WHO Pandemic Alert Level dealing with the H5N1 HPAIV epidemic has remained at Phase 3: "Human infection(s) with a new subtype, but no human-to-human spread, or at more rare instances of spread to a close contact" (WHO, 2005).

Human-to-human transmissions of HPAIV H5N1 have been found within individual families in Thailand, Indonesia and most probably China (Ungchusak et al, 2005; Normile, 2007; MacKenzie, 2008). The epidemic situation in these countries has come close to a Phase 4 Pandemic Alert: "Small cluster(s) with limited human-tohuman transmission but spread is highly localized, suggesting that the virus is not well adapted to humans" (WHO, 2005). However, because the virus has remained localized within these families, the WHO has not raised the alert level. If a Phase 4 Alert level were to be reached, it is not clear whether the small clusters of infected people could be contained locally. WHO as well as various international nongovernmental organizations (NGOs), including InSTEDD (www.instedd.org), PATH (the Bill and Melinda Gates Foundation-sponsored Program for Appropriate Technology in Health) (www.path.org/news /pr080114_flu_research.php), Global Health and Security Initiative (www.ghsi.org) and Google.org (www.google.org) (Yamada et al, 2008), are trying to prevent a Phase 5 Pandemic Alert (i.e., with a "substantial pandemic risk") in which "human-to-human spread" is 
still localized while the virus is becoming increasingly better adapted to humans, but may not be fully transmissible" (WHO, 2005). A Phase 6 situation of a full pandemic is defined as "an increased and sustained transmission in the general population" and would threaten up to half of the world's population. Although a future influenza pandemic would spread from community to community, the seriousness of the illness would depend upon the virulence of the virus (Editorial, The Lancet, 2006). The assumption that the presently observed $63 \%$ mortality rate for H5N1 HPAIV in humans (as estimated by WHO-confirmed cases) will significantly reduce as the virus spreads within the human population is not substantiated (Bergstrom, 2008; Bull and Ebert, 2008). For example, the H5N1 HPAIVs might or might not acquire the ability to transmit efficiently from human to human. Importantly, H5N1 HPAIVs have reached high prevalence in domestic and wild birds in many parts of Asia and have spread to Europe and Africa (Mills et al, 2006; WHO, 2008b).

\section{LINKING HUMAN AND ANIMAL HEALTH: THE CHALLENGE OF ZOONOTIC INFECTIONS}

Influenza is only one of the more than 200 infectious diseases transmitted between humans and animals (McMichael, 2005; Childs et al, 2007; Ellis, 2008). Given the $30 \%$ increase of newly emerging zoonotic diseases in the final third of the twentieth century, it may well be that HIV/AIDS, Ebola/Marburg/Zaire virus, West Nile virus, Severe Acute Respiratory Syndrome virus or some other new pathogens will pose a greater threat than influenza to either the human or animal kingdoms (Greenfeld, 2006; Ellis, 2008). Yet the presence of a high prevalence avian reservoir for influenza indicates that the threat of influenza is significant, and that human and animal health must be viewed as an integrated network (Gibbs, 2005; Martinot et al, 2007; Childs et al, 2007). This is critical as public health and veterinary science is moving towards the "one world, one health" concept (Enserink, 2007).

Avian influenza infections of commercial poultry already represent the largest incidence of an animal disease ever recorded, with several hundred million wild birds, geese, chickens, turkeys and ducks having died from the virus or been culled as part of the HPAIV control program (McKenzie, 2006). Furthermore, HPAIVs will remain endemic in wild birds in Asia and other parts of the world, whatever attempts are made by the authorities in these regions of the world to mitigate them. What is in question is the extent to which HPAIV will spread to humans and if so, how lethal it will be.

To date, the major attention has focused on the capacity of H5N1 HPAIVs to infect and kill humans. In investigating the January 2004 H5N1 outbreak in Vietnam, Hien et al. (2004) noted that only humans with very close contact to infected poultry died. In addition, it has been suggested that those people who become infected with H5N1 had an immune constitution particularly susceptible to the H5N1 virus (Albright et al, 2008). Such a hypothesis is based on evidence that only a few of the people reporting extensive exposure to H5N1-diseased chickens actually become ill.
In contrast, Pitzer and his colleagues (2007) could not find any evidence of human genetic susceptibility to $\mathrm{H} 5 \mathrm{~N} 1$ viruses. The crucial issue is whether a human influenza virus and an avian or animal (e.g., swine) influenza virus might reassort to create a novel reassortant virus with the capability of sustained human-to-human transmission. It appears unlikely that the wild bird/domestic duck/ chicken/human link in itself will soon create a new pandemic because after 11 years of an ongoing epidemic transmission (starting with 1997 Hong Kong outbreak), only limited human-to-human transmission has occurred. It could take decades before the "correct, i.e., humanadapted" mutations occur in the H5N1 influenza viruses (Normile, 2006; Shinya et al, 2006; van Riel et al, 2006). Swine might play a critical role as a "mixing vessel" in this evolutionary process.

\section{THE ROLE OF SWINE IN THE TRANSMISSION OF INFLUENZA A VIRUSES}

Because swine are susceptible to infection with both avian and human influenza viruses, genetic reassortment between human and avian influenza viruses can occur when these viruses co-infect an individual pig (Scholtissek, 1990). The double (avian/human; human/swine) and triple (human/avian/swine) reassortant influenza A viruses isolated from pigs in the United States or China provide supportive evidence for the "mixing vessel" theory. As early as 1919 , Koen, an inspector with the U.S. Bureau of Animal Industry, was pointing out that influenza outbreaks began with either pigs or people, but were then rapidly transferred to each other (1919). In an extensive review of avian influenza, Greger (2006) commented: "It was never clear, though, whether the pigs were the culprits or the victims. Did we infect the pigs or did they infect us". It seems that both species are able to infect each other easily (Schultz et al, 1991).

In contrast, Taubenberger and his colleagues (2005), after analyzing the complete genome of the 1918 Spanish flu virus, proposed that "the 1918 virus was not a reassortant virus (like those of the 1957 and 1968 pandemics), but more likely an entirely avian-like virus which crossed the species barrier to humans without an intermediate mammal and infected and adapted to humans." This conclusion has been challenged by Gibbs and Gibbs (2006) and Antonovics et al. (2006) who believe that Taubenberger's results suggest that "the virus began in mammals before the pandemic began and that it was a reassortant." Which kind of mammal acted as an intermediary to create the 1918 virus is still not completely understood. Subsequently, Taubenberger et al (2006) acknowledge that phylogenetic analysis alone is not sufficient to answer the question of the origin of the 1918 virus, as the avian-like virus could have infected either an unknown mammal or the human population several years before the 1918 pandemic began. They believe that adaptation of the virus occurred within a human source.

As previously noted, the viruses that caused the 1957 Asian and 1968 Hong Kong influenza pandemics are reassortant viruses of human and avian origin viruses 
(Kawaoka et al, 1989). However, to date no one knows exactly how these viruses were generated. There are two major reassortant hypotheses: 1)The AIV transmits to humans first and then reassorts with human influenza viruses; 2) Both the avian and human influenza viruses infect and reassort in an unknown mammal, for example pigs; then the novel reassortant virus is transmitted to humans (Ito et al, 1998).

The obvious potential of creating novel reassortant influenza viruses in pigs has led to the "mixing vessel" theory (Figure 1). The theory was first proposed by Scholtissek and his colleagues (1985) based on the understanding that human influenza $\mathrm{A}$ viruses do not spread easily to birds and vice versa, whereas the species barrier to pigs is rather low (Scholtissek, 1990; 1996). The antigenic and genetic similarities between certain subtypes of avian, swine and human influenza viruses and the susceptibility of swine to avian and human influenza viruses form the basis of this theory. Most avian and human influenza viruses preferentially bind to specific receptor types having $\mathrm{SA} \alpha 2,3 \mathrm{Gal}$ (avian receptor)- or SA $\alpha 2,6$ Gal (mammalian receptor)-terminated saccharides, respectively (Rogers and Paulson, 1983; Rogers and D'Souza, 1989). Both receptors have been found in the respiratory tract of swine (Ito et al, 1998), providing solid molecular evidence for pigs as "mixing vessels" for human and avian influenza viruses. Although these receptor types are also found in the respiratory tract of quail (Wan and Perez, 2006) and in humans (Shinya et al, 2006), it should be noted that pigs have been shown to transmit reassortant influenza viruses to humans (Olsen et al, 2006; Robinson et al, 2007; Swenson et al, 2008). Furthermore, humans can also transmit influenza viruses to pigs as will be discussed in the following paragraph. Zoonotic infections are not a one-way only event; they can work in both directions.

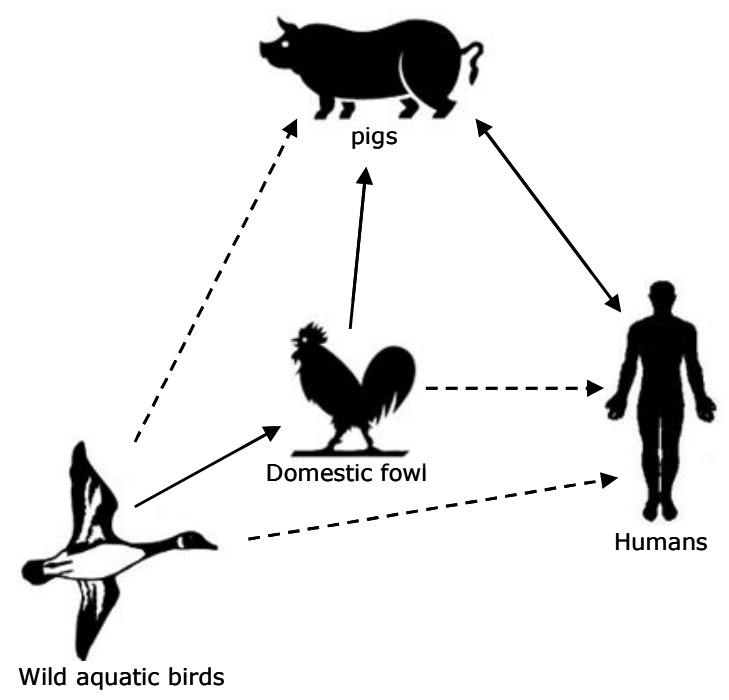

Figure 1. The pig as a "mixing vessel" for influenza A viruses. Wild aquatic birds are the natural reservoirs for influenza A virus subtypes H1-H16. Avian influenza A viruses are frequently transmitted to domestic fowl from the natural wild life reservoirs and also to pigs from domestic fowl. Human and avian influenza
A viruses can infect pigs and reassortment can occur in pigs between avian, swine and human influenza A viruses. Influenza A viruses from pigs can also infect humans. Pigs are postulated as the intermediate host, i.e., the "mixing vessel" for influenza A viruses. Avian influenza viruses from domestic fowl or wild aquatic birds occasionally transmit to humans (e.g., H5N1 virus). Solid lines; frequent and/or confirmed transmission events: Dotted lines; possible and/or occasional transmission events.

\section{Swine are susceptible to avian and human influenza $A$} viruses

Numerous laboratories have isolated wholly AIVs from swine. In addition, pigs have been experimentally infected with the H1-H13 subtypes of AIVs (Kida et al, 1994) and may be susceptible to H14-H16 subtypes as well. An H1N1 AIV that was first detected in European swine in 1979 is still circulating in European swine populations (Pensaert et al, 1981; Scholtissek et al, 1983). A different H1N1 AIV was found to have been transmitted to pigs in China in 1993 (Guan et al, 1996); H4N6, H3N3 and H1N1 AIVs were isolated from Canadian pigs in 1999, 2001 and 2002, respectively (Karasin et al, 2000; Karasin et al, 2004). Ninomiya and colleagues (2002) provided serological evidence of infection in Asian pigs with H4, H5 or H9 AIVs. Recently, an H9N2 AIV was isolated from pigs in several provinces in China (Cong et al, 2008; Xu et al, 2004; Yu et al, 2008a), and a H5N1 HPAIV was identified in pigs in Asian countries (Zhu et al, 2008). These observations have led to the conclusion that swine can serve as direct and intermediate hosts for many subtypes of AIVs including the HPAIV of the $\mathrm{H} 5$ and $\mathrm{H} 7$ subtypes. However, there is recent evidence that domestic pigs show only low susceptibility to H5N1 HPAIV (Choi et al, 2005; Lipatov et al, 2008).

The infection of pigs with wholly human viruses has also been documented. The first confirmed case of human H3N2 influenza virus occurred in Taiwanese pigs in 1970 (Kundin, 1970). Over time, human H3N2 viruses were regularly isolated from pigs and subclinical human $\mathrm{H} 3 \mathrm{~N} 2$ infections have been detected throughout the world. More recently, human-like $\mathrm{H} 3 \mathrm{~N} 2$ viruses were found in pigs from southern China (Yu et al, 2007). In addition, human $\mathrm{H} 1 \mathrm{~N} 1$ viruses have been discovered in swine populations world-wide and serological surveillance suggests that the prevailing human $\mathrm{H} 1 \mathrm{~N} 1$ viruses are readily transmitted to pigs (Brown, 2000). While pig-to-pig transmission of human H1N1 viruses has been demonstrated under experimental conditions (Kundin and Easterday, 1972), there are only a few reports of wholly human $\mathrm{H} 1$ viruses being isolated from swine (Katsuda et al, 1995; Nerome et al, 1982; Karasin et al, 2006; Yu et al, 2007). As required for the maintenance and intra-species transmission of AIVs in pigs, efficient transmission of human viruses between pigs necessitates molecular adaptation to the new host (Lipatov et al, 2004). Swine susceptibility to avian and human influenza $A$ viruses has and continues to provide opportunities for the introduction of new influenza genes into swine influenza viruses within swine. If a pig is co-infected with AIV and another disparate influenza virus strain such as a human/swine virus, a triple reassortant virus (human/avian/swine) can easily be generated and established as discussed in the next paragraph. 
Reassortment of swine/avian/human viruses occurs in the pig

Genetic reassortment among avian, human and/or swine viruses has been documented in pigs. Peiris et al (2001) found that a H9N2 AIV and contemporary human H3N2 influenza viruses were co-circulating in pigs in Southeastern China, creating an opportunity for reassortment to occur. Indeed, double reassortant $\mathrm{H} 3 \mathrm{~N} 2$ viruses containing human genes (HA and NA) and avian genes (PB2, PB1, PA, NP, M and NS), and the triple reassortant $\mathrm{H} 3 \mathrm{~N} 2$ viruses carrying human (HA and NA), swine gene (NP) and avian genes (PB2, PB1, PA, M and $\mathrm{NS}$ ) have emerged in pigs in China (Yu et al, 2008b). Genetic reassortment in pigs allows for the generation of novel influenza viruses and further demonstrates that pigs can serve as intermediate hosts and therefore as "mixing vessels" for human, swine and avian influenza viruses.

Before 1998 only classical H1N1 swine influenza viruses were isolated from the US pigs. Since 1998 the double (human/swine, subtype H3N2) and triple (avian/swine/ human, subtypes H3N2, H1N2, H1N1 and H3N1) reassortant swine influenza viruses have emerged in the United States and Canada. Presently, triple but not double reassortant swine influenza viruses have spread widely within swine across the US and Canadian swine herds. (Choi et al, 2002; Zhou et al, 1999; Karasin et al, 2006; Lekcharoensuk et al, 2006; Ma et al, 2006; Olsen et al, 2006; Webby et al, 2004). These facts provide compelling evidence that pigs could serve as a "mixing vessel" for influenza A viruses.

The double reassortant $\mathrm{H} 3 \mathrm{~N} 2$ virus was first isolated from pigs with a severe influenza-like illness on a farm in North Carolina in 1998. Genetic analysis of this virus showed that the isolate contained gene segments similar to those of the classical-swine lineage (NS, NP, M, PB2 and PA) and a recent human influenza virus (HA, NA and PB1) (Zhou et al, 1999). Subsequent triple reassortant H3N2 viruses isolated from pigs in Minnesota, Iowa and Texas contained gene segments from the classical swine virus (NS, NP and $\mathrm{M}$ ), a recent human virus (HA, NA and PB1) and an avian virus (PB2 and PA) (Zhou et al, 1999). Subsequently, the triple reassortant H3N2 viruses evolved through genetic drift and reassorted with classical H1N1 swine viruses to produce novel reassortant H1N2, H1N1 and $\mathrm{H} 3 \mathrm{~N} 1$ viruses. The triple reassortant $\mathrm{H} 3 \mathrm{~N} 2, \mathrm{H} 1 \mathrm{~N} 2$ and H1N1 viruses are the predominant subtypes circulating in the US swine population, whereas the double reassortant $\mathrm{H} 3 \mathrm{~N} 2$ viruses did not spread efficiently among swine.

One commonality among all of these novel reassortants is the maintenance of specific molecularly defined internal genes representing the PB1, PB2, PA, NP, M and NS gene segment, the so-called triple reassortant internal gene (TRIG) cassette, derived from the original triple reassortant H3N2 virus. Since 2005, introductions of human-like $\mathrm{H} 1$ viruses that are genetically and antigenically distinct from the classical swine $\mathrm{H} 1$ lineage were identified in pigs in Canada (Karasin et al, 2006) and have spread across the U.S. swine herds (Gramer, 2008). The six internal genes of these human-like $\mathrm{H} 1$ viruses appear to be similar to those found in the TRIG cassette of contemporary swine triple reassortant viruses. This would suggest that the TRIG cassette can accept multiple HA and NA types and may endow a selective advantage to swine viruses possessing them.

Surprisingly, triple reassortant $\mathrm{H} 2 \mathrm{~N} 3$ influenza viruses with leucine at position 226 and glycine at position 228 of HA, similar to early isolates of the 1957 H2N2 human pandemic, were isolated in 2006 from pigs in Missouri (Ma et al, 2007). The novel swine H2N3 viruses were able to cause disease in swine and mice, and were infectious and highly transmissible between swine and ferrets without prior adaptation. More importantly, if able to transmit to humans, $\mathrm{H} 2$ influenza viruses would pose a substantial risk because they have been absent from mammalian species since 1968 (Krauss et al, 2004; Liu et al, 2004; Munster et al, 2007), and people born after 1968 have little pre-existing immunity to the subtype.

\section{Pigs transmit influenza viruses to humans}

The transmission of swine influenza viruses to humans has been well documented. Castrucci et al (1993) and Brown et al (1998) demonstrated genetic reassortment between avian $\mathrm{H} 1 \mathrm{~N} 1$ and human $\mathrm{H} 3 \mathrm{~N} 2$ viruses in the European pigs in 1993 and 1998, respectively. The resulting double (avian/human) reassortant $\mathrm{H} 3 \mathrm{~N} 2$ viruses, with mammalian HA and NA surface glycoproteins and avian internal genes, transmitted to children in the Netherlands. Similar reassortant H3N2 viruses were subsequently isolated from humans in Hong Kong (Gregory et al, 2001), demonstrating the potential of viruses reassorted in swine to spread within mammalian populations. Also, Myers et al (2007) reported 50 cases of zoonotic swine influenza virus infections. While a few of these zoonotic swine influenza virus isolates were of the H3N2 subtype, the majority were of the H1N1 subtype. The case-fatality rate for zoonotic swine influenza virus infections in humans was $14 \%$ and the median age of patients was 24.5 years old (Myers et al, 2007). Although human swine influenza virus infections without direct swine contact are possible, most patients (61\%) with zoonotic swine influenza infections reported a recent exposure to pigs. Farmers, meat processing workers and veterinarians were found to have significantly elevated serologic titers against $\mathrm{H} 1 \mathrm{~N} 1$ and $\mathrm{H} 1 \mathrm{~N} 2$ swine influenza viruses compared to control subjects (Myers et al, 2006; Gray et al, 2007). Thus, occupational exposure to pigs may play an important role in the "mixing vessel" theory.

The transmission of influenza viruses from swine to humans is not a rare event. An H3N2 swine influenza virus containing the TRIG cassette was isolated from a 7month-old boy in Canada (Robinson et al, 2007). As the infant had no history of contact with farm animals, the virus is believed to have transmitted from human-tohuman. In another zoonotic transmission event, an H1N1 swine influenza virus, also carrying the TRIG cassette, was found to be responsible for acute respiratory illnesses in healthy pigs and humans at a 2007 Ohio county fair (Swenson et al, 2008). H1N1 viruses isolated from the sick individuals were genetically $100 \%$ identical to those harbored by the pigs, indicating that the virus was passed 
between pigs and humans at the fair. In an experimental swine infection model, the Ohio H1N1 swine influenza virus was shed at high titers and caused severe clinical disease in pigs (Vincent et al, 2008). Subsequently to this case, almost identical H1N1 swine influenza viruses were isolated from swine in several states, showing the ability of the virus to spread easily within susceptible pigs. Case reports indicate at least a $10 \%$ mortality rate with these novel Ohio-like $\mathrm{H} 1 \mathrm{~N} 1$ in finishing pigs (S Henry, personal communication), but figures for related human illnesses are unknown.

There is no direct evidence that reassortment events leading to previous pandemic viruses (such as those of the 1918,1957 or 1968 pandemics) occurred in pigs. However, reassortment of avian, human and swine viruses in the pig and subsequent molecular adaptation of the reassortant swine influenza viruses have been described. These could result in infection of humans with swinederived reassortant viruses harboring the ability to cause human-to-human transmission.

Unifying human and veterinary research and medicine HPAIV, e.g., H5N1 or H7N7 viruses, or other novel influenza viruses generated in mixing vessels (e.g. swine and quail) or transmitted directly from birds to humans clearly pose a serious threat of causing the next human influenza pandemic. However, it is not possible to predict which virus will be responsible for the next pandemic. Some scientists suggest that the danger of a sudden appearance of a wholly avian influenza virus with pandemic potential is most likely overestimated (Normile, 2005). However, this is not the prevailing scientific opinion. A recent editorial in Nature argued that "as long as $\mathrm{H} 5 \mathrm{~N} 1$ continues to be present in animals, that risk [of a pandemic] persists. And with so many other flu strains out in the world, all constantly evolving, a flu pandemic is inevitable" (Editorial, Nature, 2008).

The crux is that when a human influenza pandemic does begin, it will emerge in a non-linear fashion that will be difficult to contain (Wolf et al, 2006; Landolt and Olsen, 2007; Takeuchi and Hogeweg, 2008; Bull and Ebert, 2008). The Writing Committee of the Second WHO Consultation on Clinical Aspects of Human Infection with H5N1 AIV (2008) recently acknowledged that H5N1 viruses "are entrenched among poultry in parts of Asia, Africa, and perhaps the Middle East" and that H5N1 viruses "among birds continues to cause human disease with high mortality and to pose the threat of a pandemic". On the important question of how the H5N1 viruses infect the human respiratory tract, the Writing Committee simply notes that "the exact mode and sites of influenza A (H5N1) virus acquisition in the respiratory tract [of humans] are incompletely understood" (2008). However, it should be noted that recent studies have found that the receptors preferentially binding AIVs are located in the lower portions of the human respiratory system (Shinya et al, 2006; Gambotto et al, 2008), explaining how AIVs can directly infect humans and also why human-to-human transmission with non-adapted AIVs is rather limited. If changes were to occur in virus receptor binding affinity of AIVs that permitted replication of AIVs also in the upper human respiratory system, this would result in efficient human-to-human transmission and the possibility of a pandemic (Normile, 2006; Shinya et al, 2006; van Riel, 2006). It is precisely because both avian and human influenza A viruses have the ability to replicate effectively in the respiratory tracts of swine that pigs are a "mixing vessel" and pose a high probability of being the source of a pandemic.

Based on history, influenza is and will continue to be a serious threat to the health of many species including humans. Therefore, in both human and veterinary research, more attention needs to be given to the crossspecies transmission capacity of influenza A viruses (Osterhaus, 2001; Kuiken et al, 2006; Landolt and Olsen, 2007; Bewley, 2008; Chandrasekaran et al, 2008), especially on sources such as swine and farmed quail (Wan and Perez, 2006). Interdisciplinary research and communication between veterinary and public health professionals is essential in order to evaluate the precise danger points that could lead to the next influenza pandemic. Even though pigs can generate novel influenza viruses capable of infecting humans, at present it is difficult to predict which particular virus will cause the next human influenza pandemic. The index case ("patient zero") probably linking a wild bird, chicken or domestic duck with a pig and/or a person could be anywhere in the world, but a Southeast Asian "wet market" is most likely to be the locale in which the next pandemic virus is generated. However, recent events resulting in the establishment and isolation of a reassorted, mammalianadapted $\mathrm{H} 2 \mathrm{~N} 3$ viruses from pigs in the US should remind scientists, medical doctors, veterinarians and farmers that the creation of novel reassortant swine influenza viruses with zoonotic and pandemic potential could also happen in modern swine facilities in the backyard of a highly industrialized country in North America or Western Europe.

\section{ACKNOWLEDGEMENTS}

The authors would like to thank the National Institute of Allergy and Infectious Diseases, National Institute of Health, Department of Health and Human Services (Contract No HHSN266200700005C) and the Centers for Disease Control and Prevention (Grant No U01 CI000357-01) for their financial support of the projects described in this review. We also wish to thank Bruce Kaplan and Ralph Richardson for facilitating this interdisciplinary collaboration among the authors, and the helpful anonymous reviewers.

\section{COMPETING INTERESTS}

None declared.

\section{LIST OF ABBREVIATIONS}

HPAIV: Highly pathogenic avian influenza virus

HA: Hemagglutinin

NA: Neuraminidase

WHO: World Health Organization

TRIG: Triple reassortant internal gene 


\section{REFERENCES}

Albright FS, Orlando P, Pavia AT et al. 2008. Evidence for a heritable predisposition to death due to influenza. J Infec Dis, 197, 18-21.

Antonovics J, Hood ME and Baker CH. 2006. Molecular virology: Was the 1918 flu avian in origin? Nature, 440, E9.

Bergstrom C. 2008. Journal Club: An evolutionary biologist considers the virulence of emerging infectious diseases. Nature, 453, 261.

Bewley CA. 2008. Illuminating the switch in influenza viruses. Nature Biotechnol, 26, 60-62.

Brown IH. 2000. The epidemiology and evolution of influenza viruses in pigs. Vet Microbiol, 74, 29-46.

Brown IH, Harris PA, McCauley JW and Alexander DJ. 1998. Multiple genetic reassortment of avian and human influenza A viruses in European pigs, resulting in the emergence of an H1N2 virus of novel genotype. J Gen Virol, 79( Pt 12), 2947-2955.

Bull JJ and Ebert D. 2008. Invasion thresholds and the evolution of nonequilibrium virulence. Evol Appl 1, 172-182.

Bush RM. 2005. Influenza as a model system for studying the cross-species transfer and evolution of the SARS coronavirus, In: McLean AR, May RM, Pattison J and Weiss RA (Eds) SARS: A case study in emerging infections, Oxford University Press, Oxford, pp 24-30.

Castrucci MR, Donatelli I, Sidoli L et al. 1993. Genetic reassortment between avian and human influenza $\mathrm{A}$ viruses in Italian pigs. Virology, 193, 503-506.

Chandrasekran A, Srinivasan A, Raman R et al. 2008. Glycan topology determines human adaptation of avian $\mathrm{H} 5 \mathrm{~N} 1$ virus hemagglutinin. Nature Biotechnol, 26, 107-113.

Cheung F. 2008. Avian influenza: Straight from the dragon's mouth. Nature China, doi: 10.1038/nchina.2008.185

Childs JE, Richt JA and Mackenzie JS. 2007. Introduction: conceptualizing and portioning the eme.rgence process of zoonotic viruses from wildlife to humans. Curr Top Microbiol Immunol, 315, 1-31.

Choi YK, Goyal SM, Farnham MW and Joo HS. 2002. Phylogenetic analysis of H1N2isolates of influenza A virus from pigs in the United States. Virus Res, 87, 173-179.

Choi YK, Nguyen TD, Ozaki H, et al. 2005. Studies of H5N1 influenza virus infection of pigs by using viruses isolated in Vietnam and Thailand in 2004. J Virol, 79, 10821-10825.

Cong YL, Wang CF, Yan CM et al. 2008. Swine infection with H9N2 influenza viruses in China in 2004. Virus Genes, 36, 461-469.

Crosby AW. 1993. Influenza. In: Kiple KF (Ed) The Cambridge world history of human disease, Cambridge University Press, Cambridge, United Kingdom, p 807-811.

de Jong JC, Rimmelzwaan GF, Fouchier RAM and Osterhaus ADME. 2000. Influenza virus: a master of metamorphosis. J Infection, 40, 218-228.

Editorial. 2006. Can an influenza pandemic really be contained? The Lancet, 367,875 .

Editorial. 2008. The long war against flu. Nature, 454, 137.

Ellis KH. 2008. One health initiative will unite veterinary, human medicine. Infectious Disease News at: www.infectiousdisease news.com/200802/veterinary.asp

Enserink M. 2007. Initiative aims to merge animal and human health science to benefit both. Science, 316, 1553.

Gambotto A, Barratt-Boyes SM, de Jong MD et al. 2008. Human infection with highly pathogenic H5N1 influenza virus. The Lancet, 371, 1464-1475.

Gibbs EPJ. 2005. Emerging zoonotic epidemics in the interconnected global community. The Vet Record, 157, 673-679.

Gibbs MJ and Gibbs AJ. 2006. Molecular virology: Was the 1918 pandemic caused by bird flu? Nature, 440, E8.

Gramer MR. 2008. An update on swine influenza ecology and diagnostics. Proceeding, $39^{\text {th }}$ Annual Meeting of the American
Association of Swine Veterinarians. March 8-11, 2008, San Diego, CA, USA.

Gray GC, McCarthy T, Capuano AW et al. 2007. Swine workers and swine influenza virus infections. Emerg Infect Dis, 13, 1871-1878.

Greenfeld KT. 2006. China syndrome: the true story of the $21^{\text {st }}$ century's first great epidemic, Penguin Books, London, UK.

Greger M. 2006. Bird flu: a virus of our own hatching, Lantern Books, New York City, USA.

Gregory V, Lim W, Cameron K et al. 2001. Infection of a child in Hong Kong by an influenza A H3N2 virus closely related to viruses circulating in European pigs. J Gen Virol, 82(Pt 6), 1397-406.

Guan Y, Shortridge KF, Krauss S et al. 1996. Emergence of avian H1N1 influenza viruses in pigs in China. J Virol, 70(11), 8041-8046.

Hien TT, Liem NT, Dung NT et al. 2004. Avian Influenza (H5N1) in 10 patients in Vietnam. N Engl J Med, 350(12), 1179-1188.

Hilleman MR. 2002. Realities and enigmas of human viral influenza: pathogenesis, epidemiology and control. Vaccine, 20, 3068-3087.

Horimoto T and Kawaoka Y. 2005. Influenza: Lessons from past pandemics, warnings from current incidents. Nature Reviews Microbiology, 3, 591-600.

Hulse-Post DJ, Sturm-Ramirez KM, Humberd J et al. 2005. Role of domestic ducks in the propagation and biological evolution of highly pathogenic H5N1 influenza viruses in Asia. PNAS, 102, 10682-10687.

Ito T, Couceiro JNSS, Kelm S et al. 1998. Molecular basis for the generation in pigs of influenza $\mathrm{A}$ viruses with pandemic potential. J Virol, 72, 7367-7373.

Jennings LC, Monto AS, Chan PKS et al. 2008. Stockpiling prepandemic influenza vaccines: A new cornerstone of pandemic preparedness plans. Lancet Infect Dis, 8, 650-658.

Karasin AI, Brown IH, Carman S et al. 2000: Isolation and characterization of H4N6 avian influenza viruses from pigs with pneumonia in Canada. J Virol, 74, 9322-9327.

Karasin AI, Carman S and Olsen CW. 2006. Identification of human H1N2 and human-swine reassortant H1N2 and H1N1 influenza A viruses among pigs in Ontario, Canada (2003 to 2005). J Clin Microbiol, 44, 1123-1126.

Karasin AI, West K, Carman S and Olsen CW. 2004 Characterization of avian $\mathrm{H} 3 \mathrm{~N} 3$ and $\mathrm{H} 1 \mathrm{~N} 1$ influenza $\mathrm{A}$ viruses isolated from pigs in Canada. J Clin Microbiol, 42, 4349-4354.

Katsuda K, Sato S, Shirahata T et al. 1995: Antigenic and genetic characteristics of $\mathrm{H} 1 \mathrm{~N} 1$ human influenza virus isolated from pigs in Japan. J Gen Virol, 76 ( Pt 5), 1247 1249.

Kawaoka Y, Krauss S and Webster RG. 1989. Avian-to-Human Transmission of the PB1 Gene of Influenza A Viruses in the 1957 and 1968 Pandemics. J Virol, 63, 4603-4608.

Kida H, Ito T, Yasuda J et al. 1994. Potential for transmission of avian influenza viruses to pigs. J Gen Virol, 75 (Pt 9), 2183-2188.

Koen JS. 1919. A practical method for field diagnosis of swine disease. Amer J Vet Sci, 14, 468.

Korteweg C and Gu J. 2008. Pathology, molecular biology, and pathogenesis of avian influenza A (H5N1) infection in humans. Amer J Pathol, 172, 1155-1170.

Krauss S, Walker D, Pryor SP et al. 2004. Influenza A viruses of migrating wild aquatic birds in North America. Vector Borne Zoonotic Dis, 4, 177-189.

Kuiken T, Holmes EC, McCauley J et al. 2006. Host species barriers to influenza virus infections. Science, 312, 394-397.

Kundin WD. 1970. Hong Kong A-2 influenza virus infection among swine during a human epidemic in Taiwan. Nature, 228, 857.

Kundin WD and Easterday BC. 1972: Hong Kong influenza infection in swine: experimental and field observations. Bull World Health Organ, 47, 489-491. 
Landolt GA and Olsen CW. 2007. Up to new tricks-A review of cross-species transmission of influenza A viruses. Animal Health Res Rev, 8, 1-21.

Lau EHY, Leung YHC, Zhang LJ et al. 2007. Effect of interventions on influenza A (H9N2) isolation in Hong Kong's live poultry markets, 1999-2005. Emerg Infect Dis, 13, 1340-1347.

Lekcharoensuk P, Lager KM, Vemulapalli R, et al. 2006. Novel swine influenza virus subtype H3N1, United States. Emerg Infect Dis 12(5), 787-794.

Lina B. 2008. History of influenza pandemics. In: Raoult D and Drancourt M (Eds) Paleomicrobiology: Past human infections, Springer, Marseilles, France, pp 199-211.

Lipatov AS, Govorkova EA, Webby RJ et al. 2004. Influenza: Emergence and control. J Virol, 78, 8951-8959.

Lipatov AS, Kwon YK, Sarmento LV et al. 2008. Domestic pigs have low susceptibility to $\mathrm{H} 5 \mathrm{~N} 1$ highly pathogenic avian influenza viruses. PLoS Pathog 4, e1000102.

Liu JH, Okazaki K, Bai GR et al. 2004. Interregional transmission of the internal protein genes of $\mathrm{H} 2$ influenza virus in migratory ducks from North America to Eurasia. Virus Genes, 29, 81-86.

Ma W, Gramer M, Rossow K and Yoon KJ. 2006. Isolation and genetic characterization of new reassortant $\mathrm{H} 3 \mathrm{~N} 1$ swine influenza virus from pigs in the Midwestern United States. J Virol, 80, 5092-5096.

Ma W, Vincent AL, Gramer MR et al. 2007. Identification of $\mathrm{H} 2 \mathrm{~N} 3$ influenza A viruses from swine in the United States. PNAS, 104, 20949-20954.

MacKenzie D. 2006. The bird flu threat. New Scientist, Special Sup, 7 January, p i-vii.

MacKenzie D. 2008. Bird flu may spread within families. New Scientist.com news service, 8 April at: www.newscientist.com /channel/health/dn13612-bird-flu-may-spread-within-families Html.

Martinot A, Thomas J, Thiermann DVM and Dasgupta N. 2007. Prevention and control of avian influenza: the need for a paradigm shift in pandemic influenza preparedness. The Vet Record, 160, 343-345.

McKibbon W and Sidorenko A. 2006. Global macroeconomic consequences of pandemic influenza. Lowy Institute for International Policy, Sydney, Australia at: www.lowyinstitute. org/Publication.asp?pid=345.

McMichael, AJ. 2005. Environmental and social influences on emerging infectious diseases: past, present, and future. In: McLean AR, May RM, Pattison J and Weiss RA (Eds) SARS: $A$ case study in emerging infections, Oxford University Press, Oxford, p 4-15.

Mills CE, Robins JM, Bergstrom CT and Lipsitch M. 2006 Pandemic influenza: risk of multiple introductions and the need to prepare for them. PLoS Med, 3, e135.

Morse SS. 2007. Pandemic influenza: studying the lessons of history. Proc Natl Acad Sci USA, 104, 7313-7314.

Munster VJ, Baas C, Lexmond P et al. 2007. Spatial, temporal, and species variation in prevalence of influenza $\mathrm{A}$ viruses in wild migratory birds. PLoS Pathog, 3, e61.

Myers KP, Olsen CW, Setterquist SF et al. 2006. Are swine workers in the United States at increased risk of infection with zoonotic influenza virus? Clin Infect Dis, 42, 14-20.

Myers KP, Olsen CW and Gray GC. 2007. Cases of swine influenza in humans: a review of the literature. Clin Infect Dis, 44, 1084-1088.

Nerome K, Ishida M, Oya A et al. 1982: Isolation of an influenza H1N1 virus from a pig. Virology, 117(2), 485-489.

Ninomiya A, Takada A, Okazaki K et al. 2002. Seroepidemiological evidence of avian $\mathrm{H} 4, \mathrm{H} 5$, and $\mathrm{H} 9$ influenza A virus transmission to pigs in southeastern China. Vet Microbiol, $88,107-114$

Normile D. 2005. Pandemic skeptics warn against crying wolf. Science, 310, 1112-1113.
Normile D. 2006. Studies suggest why few humans catch the H5N1 virus. Science, 311, 1692.

Normile D. 2007. Indonesia taps village wisdom to flight bird flu. Science, 315, 30-33.

Olsen CW, Karasin AI, Carman S et al. 2006. Triple reassortant H3N2 influenza A viruses, Canada, 2005. Emerg Infect Dis, 12, $1132-1135$.

Osterhaus A. 2001. Catastrophes after crossing species barriers. Phil Trans R Soc Lond B, 356, 791-793.

Peiris JS, Guan Y, Markwell D et al. 2001. Cocirculation of avian H9N2 and contemporary "human" H3N2 influenza A viruses in pigs in southeastern China: potential for genetic reassortment? J Virol, 75, 9679-9686.

Pensaert M, Ottis K, Vandeputte J et al. 1981. Evidence for the natural transmission of influenza A virus from wild ducts to swine and its potential importance for man. Bull World Health Organ, 59, 75-78.

Quinn T. 2008. Flu: A social history of influenza. New Holland Publishers (UK) Ltd, ISBN: 978-1845379414

Pitzer VE, Olsen SJ, Bergstrom CT et al. 2007. Little evidence for genetic susceptibility to influenza A (H5N1) from family clustering data. Emerg Infect Dis, 13, 1074-1076.

Robinson JL, Lee BE, Patel J et al. 2007. Swine influenza (H3N2) infection in a child and possible community transmission, Canada. Emerg Infect Dis, 13, 1865-1870.

Rogers GN and Paulson JC. 1983. Receptor determinants of human and animal influenza virus isolates: Differences in receptor specificity of the $\mathrm{H} 3$ hemagglutinin based on species of origin. Virology, 127, 361-73.

Rogers GN and D'Souza BL. 1989. Receptor binding properties of human and animal H1 influenza virus isolates. Virology, $173,317-322$

Scholtissek C. 1990. Pigs as the 'mixing vessel' for the creation of new pandemic influenza A viruses. Med Princip Prac, 2, 65-71.

Scholtissek C. 1996. Molecular evolution of influenza viruses. Virus Genes, 11, 209-215.

Scholtissek C, Bürger H, Bachmann PA and Hannoun C. 1983. Genetic relatedness of hemagglutinins of the H1 subtype of influenza A viruses isolated from swine and birds. Virology, 129, 521-3.

Scholtissek C, Bürger H, Kistner O and Shortridge KF. 1985. The nucleoprotein as a possible major factor in determining host specificity of influenza H3N2 viruses. Virology, 147, 287 294.

Schultz U, Fitch WM, Ludwig S et al. 1991. Evolution of pig influenza viruses, Virology, 183, 61-73.

Shinya S, Ebinall M, Yamada S et al. 2006. Influenza virus receptors in the human airway. Nature, 440, 435-436.

Swenson SL, Landgraf JG, Killian ML et al. 2008. Swine influenza virus infection of pigs and people at a county fair. Proceeding of $39^{\text {th }}$ Annual Meeting of the American Association of Swine Veterinarians, March 8-11 2008, San Diego, CA, USA.

Takeuchi N and Hogeweg P. 2008. Evolution of complexity in RNA-like replicator systems. Biology Direct, 3, 11, at: www.biology-direct.com.

Taubenberger JK, Reid AH, Lourens RM et al. 2005. Characterization of the 1918 influenza virus polymerase genes. Nature, 437, 889-893.

Taubenberger JK, Reid AH, Lourens RM et al. 2006. Molecular virology: Was the 1918 pandemic caused by a bird flu? Was the 1918 flu avian in origin? (Reply). Nature, 440, E9-E10.

Tumpey TT, Basler CFk, Aguillar PV et al. 2005. Characterization of the reconstructed 1918 Spanish influenza pandemic virus. Science, 310, 77-80.

Ungchusak K, Auewarakul MD, Dowell SF at al. 2005. Probable person-to-person transmission of avian influenza A (H5N1). N Engl J Med, 352, 332-340.

van Riel D, Munster VJ, de Wit E et al. 2006. H5N1 virus attachment to lower respiratory tract. Science, 312, 399-400. 
Vincent AL, Swenson SL, Lager KM et al. 2008. Experimental evaluation of a swine influenza virus isolated from a county fair outbreak in the United States. Proceedings of $20^{\text {th }}$ International Pig Veterinary Society Congress, 22-26 June 2008. Durban, South Africa.

Wan H and Perez DR. 2006. Quail carry sialic acid receptors compatible with binding of avian and human influenza viruses. Virology, 346, 278-286.

Wan H, Sorrell EM, Song $\mathrm{H}$ et al. 2008. Replication and transmission of H9N2 influenza viruses in ferrets: Evaluation of pandemic potential. PLoS ONE, 3, e2923.

Webby RJ, Rossow K, Erickson G et al. 2004. Multiple lineages of antigenically and genetically diverse influenza A virus cocirculate in the United States swine population. Virus Res, 103, 67-73.

Webby RJ, Webster RG and Richt JA. 2007. Influenza viruses in animal wildlife Populations. Curr Top Microbiol Immunol, 315, 67-83.

Webster RG. 2004. Wet markets-a continuing source of severe acute respiratory syndrome and influenza? The Lancet, 363, 234-236.

Webster RG, Peiris M, Chen H and Guan Y. 2006. H5N1 outbreaks and enzootic influenza. Emerg Infect Dis, 12, 3-8.

WHO Department of Communicable Disease Surveillance and Response, Global Influenza Program. 2005. WHO global influenza preparedness plan: The role of WHO and recommendations for national measures before and during pandemics at: www.who.int/csr/resources/publications influenza/WHO_CDS_CSR_GIP_2005_5/en/index.html.

WHO Epidemic and Pandemic Alert and Response. 2008a. Cumulative number of confirmed human cases of avian influenza $\mathrm{A} /(\mathrm{H} 5 \mathrm{~N} 1)$ reported to $\mathrm{WHO}$ at: http://www.who.int/ csr/disease/avian influenza/country/cases table 2008 09 10/e n/index.html.

WHO Epidemic and Pandemic Alert and Response. 2008b. World: Areas reporting confirmed occurrence of H5N1 avian influenza in poultry and wild birds since 2003, status as of 03.10.2008. Public Health Mapping and GIS Map Library at:
http:/gamapserver.who.int/mapLibrary/Files/Maps/Global_Sub Nat_H5N1inAnimalConfirmedCUMULATIVE_20081003.png. Wolf YI, Viboud C, Holmes EC et al. 2006. Long intervals of stasis punctuated by bursts of positive selection in the seasonal evolution of influenza A virus. Biology Direct, 1, 34, at: www.biology-direct.com.

Writing Committee of the Second World Health Organization Consultation on Clinical Aspects of Human Infection with Avian Influenza A (H5N1) Virus. 2008. Update on avian influenza A $(\mathrm{H} 5 \mathrm{~N} 1)$ virus infection in humans. N Engl Med, 358, 261-273.

Wu WL, Chen Y, Wang P et al. 2008. Antigenic profile of avian H5N1 viruses in Asia from 2002 to 2007. J Virol, 82, 1798-1807.

Xu C, Fan W, Wei R and Zhao H. 2004. Isolation and identification of swine influenza recombinant $\mathrm{A} / \mathrm{Swine}$ /Shandong/1/2003(H9N2) virus. Microbes Infect, 6, 919-25.

Yamada T, Dauty A and Walport M. 2008. Ready for avian flu? Nature, 454, 162

Yang ZY, Wei CJ, Kong WP et al. 2007. Immunization by avian H5 influenza hemagglutinin mutants with altered receptor binding specificity. Science, 317, 825-828.

$\mathrm{Yu} \mathrm{H}$, Hua RH, Wei TC et al. 2008a. Isolation and genetic characterization of avian origin H9N2 influenza viruses from pigs in China. Vet Microbiol, 131, 82-92.

Yu H, Hua H, Zhang Q et al. 2008b. Genetic evolution of swine influenza A (H3N2) viruses in China from 1970 to 2006. J Clin Microbiol, 46, 1067-1075.

$\mathrm{Yu} \mathrm{H}$, Zhang GH, Hua RH et al. 2007. Isolation and genetic analysis of human origin H1N1 and H3N2 influenza viruses from pigs in China. Biochem Biophys Res Commun, 356, 91-96.

Zhou NN, Senne DA, Landgraf JS et al. 1999. Genetic reassortment of avian, swine, and human influenza A viruses in American pigs. J Virol, 73, 8851-8856.

Zhu Q, Yang H, Chen W et al. 2008. A naturally occurring deletion in its NS gene contributes to the attenuation of an H5N1 swine influenza virus in chickens. J Virol, 82, 220-228. 